\title{
ヒメアカホシテントゥの羽化率に影響する要因について
}

\author{
田非学・和田健志 (果樹試験場・ロ之津支場)
}

\section{Factors affecting the rate of emergence of Chilocorus kuwanae Silvestri (Coccinellidae) in an insectary}

\section{Manabu TaNAKA and Kenji WADA (Kuchinotsu Branch, Fruit Tree Research Station)}

The lady beetle, Chilocorus kuwanae, is the most efficient native predator of Unaspis yanonensis on citrus trees in Japan. Some biological and physical factors affecting the rate of emergence of the beetle were investigated for mass production. The condition above $70 \%$ of relative humidity during the larval and pupal periods resulted in the higher rate of adult emergence. Other factors such as sources of insect stocks, age of prey scale (Chrysomphalus bifasciculatus) as food, rearing density of larvae, and photoperiod treatment during the larval stage seemed to have a little effect upon the rate.

農薬偏重の防除体系を改善する目的でいろいろな防除 法が研究されている。藷者らはカンキツ類の重要㫪虫で あるヤノネカイガラムシの生物農薬として，ヒメアカホ シテントウを大量に堌殖し利用することを試みている。

しかし1971年の試験で，このテントウムシの羽化率が 非常に低い估を示し大量堌殖上大きな支障となった。そ こでこの羽化率に影響を及ばすと考えられるいくつかの 要因について検討した。すなわち累代飼育による母蝰

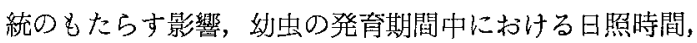
餌の栄養, 1 令幼虫の力ボチャ 1 個当りの接種数, 生育 時の湿度などの各要母について試験したのでその概要を 報告する。

本文に入るに先だち，史験の手位いをしていただいた 当支場虫害研究宝の研修生諸氏に心からお礼申しあげる。

\section{材 料と 方 法}

各試験とも温度 $25^{\circ} \mathrm{C}$ ，湿度 $55 \sim 65 \% \mathrm{RH} ， 24$ 時間照明 の天敵飼育空で行ない，カボチャ上で増殖したトビイロ マルカイガうムシを与え飼育した。

\section{1. 母虫の系統による羽化率の比較}

母虫には 1 ) 1972年 6 月久留米市高良内放任園加採 集したもの，2）当飼育室で多裹・多食系統として選抜 しているもの，3）当飼育室で永年累代飼育しているも のを用いた。この3系統から得られた次世代のふ化栋虫 をカボチャ上で增殖したトビイロマルカイガラムシに各 区 50 頭接種し，直径 $20 \mathrm{~cm}$, 高さ $15.5 \mathrm{~cm}$ のプラスチック製 ポットに入れて，2 反復ずつ試験した。1 令加ら4 令ま では $2 \sim 3$ 日間隔，蛹から羽化までは毎日备ステージに ついて生死を調查した。

\section{2. 生育時の日照時間による羽化率の比較}

$40 ワ ッ ト の$ 白色螢光燈 2 本をカボチャの上端から $50 \mathrm{~cm}$ の距離におき，2,000ルックスに保ち $0,8,12,16,24$
時間照明した。各区ともテントウムシの妙虫をカボチャ 1 個当り 30 頭接種し，毎日その生死について調査した。

3. 餌であるトビイロマルカイガラムシの日令の差に よる羽化率試験

カボチャに接種して30，40，50，60，70日を経過した トビイロマルカイガラムシを与え前記した容器内で，カ ボチャ1個当り 30 頭接種した。調疽はデントウムシの生 死について每日行なった。

\section{4. 幼虫密度による羽化率の比較}

力ボチャ1個当りテントウムシのS化約忠を 20,30 , $40 ， 50 ， 100$ 頭接種し，毎日その生死について調查した。

\section{5. 湿度と羽化率の比較}

湿度の調節は口径 $30 \mathrm{~cm}$ のデシケーターで硫酸法を朋い た。次に示すようにテントウムシのステージ別に試験を 開始した。1）蛹から開始した試験一 5 個体ずつプラス チック製カップ（值径 $7 \mathrm{~cm} ，$ 高さ $4 \mathrm{~cm}$ ) に入れ $50 ， 60$ ， $70,80,90 \% \mathrm{RH}$ に湿度を保ったデシケーター内に入 れた。反復は 4 とし，羽化までの日数，死亡率，奇型率 を調查した。2）3令㭃虫から閉始した試験一慨がつい たカボチャを 8 等分して，3命妃出を10頭ずつ接種した。 慨は腐敗が始まると同時に取り挨えた。湿度は力ボチャ の呼吸のため多少のふれが生じたがその值は Fig. 4 に 示した。なお各ステージの生死を毎日調查した。

\section{結果および考察}

\section{1. 母虫の系統による羽化率の比較}

野外，多座・多食，室内の3 系統を母出とし羽化率を 比較した結果を Fig. 1 に示した。3系統とも㭃虫の生 育率は80\%以上と高く，また蛹化率も70\%以上の值を示 している。しかし羽化率は非常に低く，3者の䦬に有意 差は認められなかった。これらのことからヒメアカホシ テントウの羽化率の低下は累代飼育による影響とは思わ 


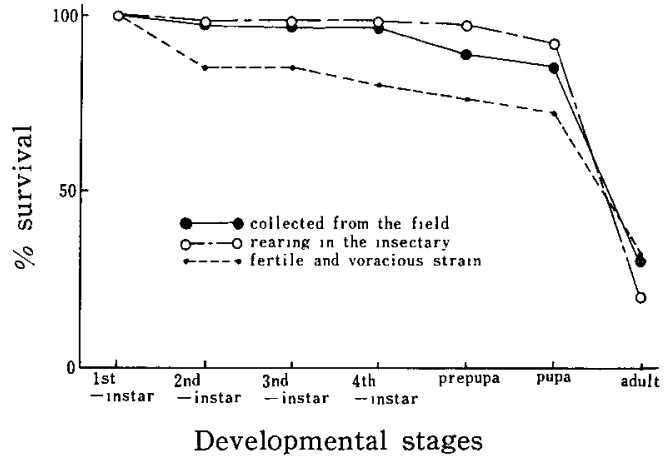

Fig. 1. Survival curves of three stocks of C. kuwanae

れない。

\section{2. 生育時の日照時間による羽化率の比較}

Tablc 1 に示すようにこの誈験は各区とも将化個体が まったくみられなかった。しかしその前段階である蛸化 率で比較してみると，12時間照明区で蛹化個体が最も多 く概して12時間以下の照明下で飼育すると蛹化数が少な くなった。以上のことからヒメアカホシテントウの羽化 は白色螢光燈 2,000 ルックスの照明という条件下では直 接影響されていないが幼虫の生青，あるいは蛹化は長い 照明時間が有利と考えられる。

Table 1. Effect of day-length during the larval period on the development of $C$. kuwanae

\begin{tabular}{ccccc}
\hline \hline $\begin{array}{c}\text { Day- } \\
\text { length } \\
\text { (hrs.) }\end{array}$ & $\begin{array}{c}\text { No. of } \\
\text { larvae } \\
\text { tested }\end{array}$ & $\begin{array}{c}\text { No. of } \\
\text { pupae } \\
\text { formed }\end{array}$ & $\begin{array}{c}\% \text { of } \\
\text { pupation }\end{array}$ & $\begin{array}{c}\text { No. of } \\
\text { adults } \\
\text { emerged }\end{array}$ \\
\hline 0 & 30 & 11 & 37 & 0 \\
8 & 30 & 16 & 53 & 0 \\
12 & 30 & 25 & 83 & 0 \\
16 & 30 & 18 & 60 & 0 \\
24 & 30 & 22 & 73 & 0 \\
\hline
\end{tabular}

3. トビイロマルカイガラムシの日令の差による羽化 率の比較

Table 2 に示すようにトビイロマルカイガラムシはカ
ボチャに接種してから，40日程度で成虫となり，60日を 経過すると次代の歩行幼虫が現われる。羽化・蛹化はこ のカイガラムシの日令によっていくらかの差が見られた。 すなわち日令の若いものを䬣として与无た区で少数の羽 化個体吕見られ，蛹化率は歩行約虫の出現する60日を越 すと低くなった。以上のことから幼虫の発育には日令の 若いものが有利であるが，この試験から羽化率がどれほ ぞその影響を受けているかの推測红難しい。

\section{4. 幼虫密度による羽化率の比較}

結果は Fig. 2 に示した。カボチャ 1 個当りテントウ ムシのふ化幼虫 $30 ， 50$ 頭接種した区で羽化率か低くなっ ているが，その他の区とくに 100 頭区で $80 \%$ 近い羽化率 が見られたことから，カボチャ 1 個当り 100 頭以内であ れば，羽化に影響があるとは思われない。

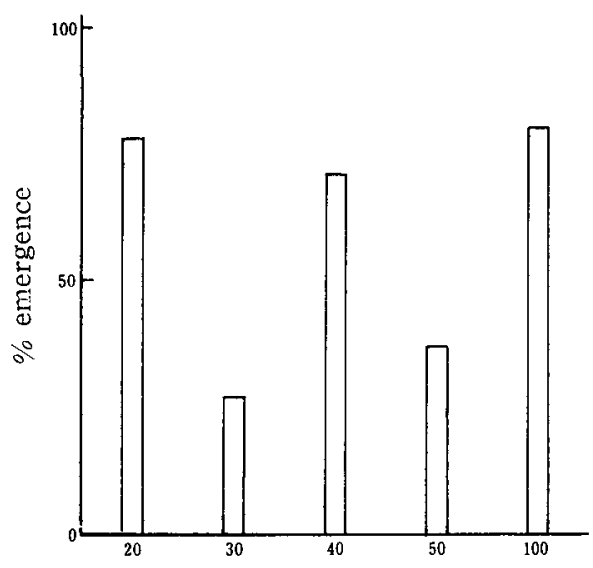

No. of larvae

Fig. 2. Effect of rearing density of larvae on the rate of adult emergence of C. kuwanae

\section{5. 湿度と羽化率の試験}

Fig. 3 に示すように蛹加ら開始した試験の羽化率は 低湿度で低い值を示した。また奇型個体の出現は50，60 \%区だけで見られた。さらに蛹期間は低湿度ほど長く， 温度が高くなるにつれて少しずつではあるが短縮されて

Table 2. Effect of age of prey, C. bifasciculatus, on the development of $C$. kuwanae

\begin{tabular}{ccccccc}
\hline \hline \multicolumn{2}{c}{ Chrysomphalus bifasciculatus } & \multicolumn{4}{c}{ Chilocorus kuwanae } \\
\hline $\begin{array}{l}\text { Days after } \\
\text { inoculation }\end{array}$ & Age of prey & $\begin{array}{c}\text { No. of } \\
\text { larvae } \\
\text { tested }\end{array}$ & $\begin{array}{c}\text { No. of } \\
\text { pupae } \\
\text { formed }\end{array}$ & $\begin{array}{c}\% \text { of } \\
\text { pupation }\end{array}$ & $\begin{array}{l}\text { No. of } \\
\text { adults } \\
\text { emerged }\end{array}$ & $\begin{array}{c}\% \text { of } \\
\text { emergence }\end{array}$ \\
\hline 30 & 1st, 2nd-instar & 50 & 40 & 80 & 3 & 6 \\
40 & 3rd-instar, adult & 50 & 26 & 52 & 1 & 2 \\
50 & adult & 50 & 32 & 64 & 0 & 0 \\
60 & adult, lst, 2nd-instar & 50 & 13 & 26 & 0 & 0 \\
70 & (offspring) & 50 & 15 & 30 & 0 & 0 \\
\hline
\end{tabular}


いる。次にFig. 4 に示すように 3 令幼虫からの琙験で は低湿度と高湿度の生育率・羽化率の差は大きくなり， 低湿度がヒメアカホシテントウの生忩わよび羽化に影悲 をもたらしていることが垫められた。またこの試験から 適湿は70〜90\% RH と思われるが，80\%以上の高湿度 の場合はカビの発生，カボチャの噟敗などが見られるた め，奏用的には70 80\% RHであろう。
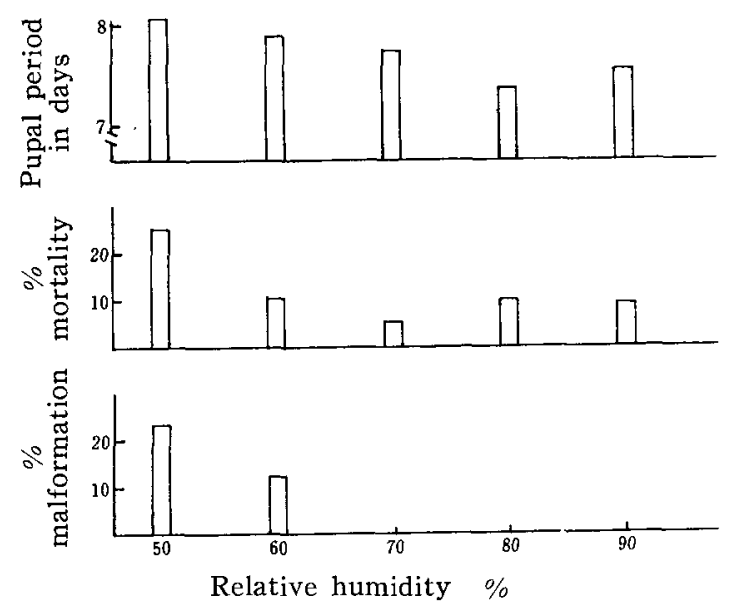

Fig. 3. Effect of relative humidity during pupal period on the development of C. kuwanae

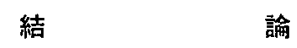

以上の試験の結果からヒメアカホシテントウの羽化率 に及添す要因すなわち，母虫，日長，慨の品質，密度効

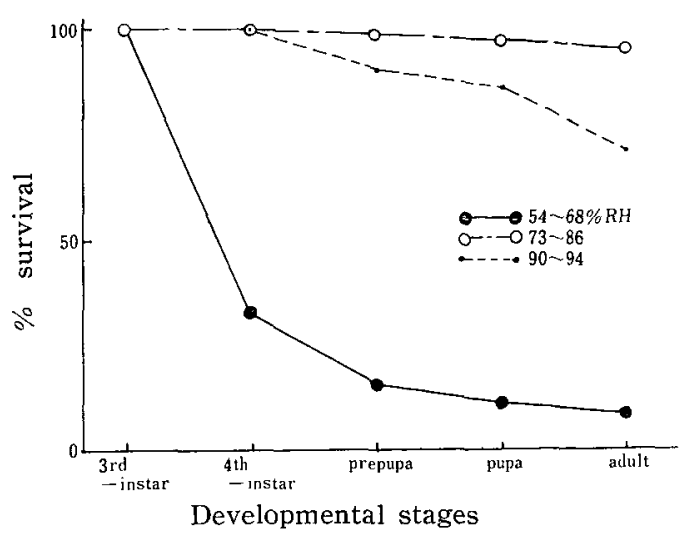

Fig. 4. Survival curves of C. kuwanae from the 3 rd instar larvae reared under the different relative humidity

果にははとんど影響されていないと思われる。Hodek (1958), Sethi (1964) によるアブラムシ捕食性テント ウムシでは，湿度による生育，羽化はほとんど影響され でないことが報告されている。しかし本試験の結果, かなり影響を受けていることが明らかになった。なお， ヒメアカホシテントゥの羽化に及将す各種要团について の影響は未知の点があると思わ㧈，今後の研究にまたね ばならない。

\section{引用文 献}

1) Hodek, I. (1958) Acta. Soc. ent. jugosl. 55: $121 \sim 141$. 2) Sethi, S. L. , and Atwal, A.S. (1964) Indian. J. agric. Sci., 34: 166 171.

\section{カンキッ園の捕 食性ダニの種類と分布 田非学・井上，晃一(果樹試験場口之津支場)}

\section{Fauna and distribution of predacious mites on tree crown in the citrus area of the southern part of Japan}

Manabu TANAKA and Kouichi InOue (Kuchinotsu Branch, Fruit Tree Research Station)

In the citrus area of the southern part of Japan, five species of predacious mites were found; Amblyseius largoensis (Muma), Amblyseius sp., Agistemus exsertus González-Rodríguez, Agistemus terminalis (Quayle) and Anystis sp.. A. largoensis and A. terminalis were dominant species. $A$. largoensis was found numerous especially in unsprayed grove. Distribution of A. largoensis on citrus tree crown was investigated. It was found that this predacious mites were abundant at lower inside parts of tree crown in contrast with the fact that the citrus red mite, Panonychus citri ( $M c$ Gregor), has much wider distribution on tree crown.

カンキツ園に見受けられる武食性ダニには，ハダ二類 の天敵として重要な種類が含まれており，これまでにカ ブリダニ科およびナガヒシダ二科に属するもの，それぞ れ数種が Ehara (1958，1959，1962，1964）および森
ら（1964）によって報告されている。これら捕食性ダニ のなかでも，カブリダニ科のものは一般に種類が多いこ とが知られているので, 今後カンキツ園で探萗される未 知天敵のなかには有望な種類が存在する可能性も考えら 